www.jmscr.igmpublication.org

Impact Factor 5.84

Index Copernicus Value: 71.58

ISSN (e)-2347-176x ISSN (p) 2455-0450

crossref DOI: _https://dx.doi.org/10.18535/jmscr/v5i11.157

Journal Of Medical Science And Clinical Research

IGM Publication

An Official Publication of IGM Publication

\title{
Predictors of Axillary Lymph Node Status in Early Breast Cancer: A Single Center Analysis of 81 patients at a Tertiary Care Hospital in North-East India
}

\author{
Authors \\ Sapam Opendro Singh ${ }^{1}$, Verma Nityanand ${ }^{2}$, Lalsangzuala Tochhawng ${ }^{2}$, Rina Tomeru ${ }^{2}$, \\ Longjam Anil Singh ${ }^{2}$, Th Sudhir Chandra Singh ${ }^{3}$ \\ ${ }^{1}$ AssociateProfessor, ${ }^{2}$ Post-graduate trainees, ${ }^{3}$ Professor \\ Department of Surgery, Regional Institute of Medical Sciences, Imphal, Manipur, India
}

Email: nityanandverma7@gmail.com

\begin{abstract}
Breast cancer is the most common site specific cancer in women. Mastectomy with axillary lymph node dissection (ALND) is the gold standard in determining the prognosis, adjuvant therapy and loco-regional control and improves the survival rate among the node positive group. But, those patients who do not have axillary metastasis may not benefit from ALND instead they may suffer from its complications. Therefore, it may be overtreatment to perform ALND in this subgroup of patients. This study was done to find out the predictors of axillary lymph node metastases in early breast cancer which will help in selecting patients in whom ALND can be avoided. 81 early breast cancer patients who were operated between January 2010 to March 2017 were included in this study. 25 patients (30.9\%) showed axillary metastasis. On statistical analysis, tumor size $(p=0.045)$, hormonal status $(p=0.023)$ and histological type of the tumor $(p=0.038)$ were found to be significant. Whereas Other variables like age of the patient, histological grading of the tumor, side of the breast involved, lymphovascular invasion and perineural spread were not found to be associated with axillary lymph node metastasis in early breast cancer.In conclusion, we have found that size of the tumor, hormonal status and histological type of the tumor can predict the axillary metastasis in early breast cancer which can be taken into consideration before going for ALND in node negative patients.
\end{abstract}

Keywords: Breast cancer, axillary lymph node dissection (ALND), histopathological type, lymphovascular invasion, perineural spread, immunohistochemistry

\section{Introduction}

Breast cancer is the most common site-specific cancer in women and is the leading cause of death from cancer for women aged 20-59 years. It accounts for $29 \%$ of all newly diagnosed cancers in females and is responsible for $14 \%$ of the cancer related deaths in women ${ }^{[1]}$. In 2001 , it was estimated that there were approximately 80000 new breast cancer cases in India ${ }^{[2]}$. Due to the easy availability of screening facilities such as mammography and awareness campaigns of mass and media, most of the breast cancers are detected at early stages now a days. Also, there are established prognostic factors such as lymph node status, tumor size, lymphovascular invasion, age, ER/PR and Her2/neu status that determine the 
aggressiveness of the therapy to be given and outcome of the disease ${ }^{[3]}$. Axillary Lymph Node Dissection (ALND) remains the best way to evaluate the presence of nodal metastases and in loco-regional disease control. However, it is associated with complications such as lymphedema, shoulder stiffness, breast edema, seroma formation, upper limb numbness and brachial plexopathy ${ }^{[4,5]}$. Sentinel Lymph Node Biopsy (SLNB) using a blue dye, a radiolabeled colloid or both has become an acceptable alternative to routine level I and II ALND for patients with clinically node negative breast cancer ${ }^{[6,7]}$. SLNB has been shown to be associated with considerably less morbidity compared to ALND. However, SLNB still has a significant association with lymphedema ${ }^{[8]}$. In addition, SLNB demands technical expertise, increases the complexity and cost of the surgical procedure, has chance of false negative result and in some patients, itnecessitates a second surgery for a completion axillary dissection ${ }^{[9]}$. Thus, ALND or SLNB may not benefit the patients with negative axilla, instead they may suffer from its complications. Therefore, it may be considered an overtreatment to perform ALND or SLNB in patients with negative axilla.

The aim of this study is to find out the predictors of axillary lymph node metastases in early breast cancer which will help in selecting patients in whom ALND or SLNB can be of use and in those where it can be avoided.

\section{Material and Methods}

The study is a retrospective study carried out at Regional Institute of Medical Sciences, Imphal, Manipur, India from January 2010 to March 2017. Out of 144 breast cancer cases operated during the stdudy period, 81early breast cancer patients who underwent modified radical mastectomy or breast conservation surgery with ALND were included in the study. Patients with palpable axillary lymph nodes, locally advanced diseases, distant metastasis and male breast cancer patients were excluded from the study. Study variables included patient's age, tumor size, side of the breast involved, histopathological type, histological grade, ER/PR and Her2/neu status, perineural spread and lymphovascular invasion which were correlated with the axillary lymph node status. All these data were collected retrospectively from the available clinical and histopathological examnation (HPE) reports and modified Scarff-Bloom-Richardson's score was used for the histological grading of the tumour. The breast cancer was classified as per the WHO guidelines into DCIS (ductal carcinoma in situ), infiltrating ductal carcinoma-NOS, infiltrating lobular carcinoma, medullary, mucinous, tubular and metaplastic carcinoma. Immunohistochemicalstaining for ER (Biogenex clone: 1D5) and for PR (Biogenex clone: PR88) was done using Streptavidin- Biotin Immunoperoxidase procedure. Immunohistochemical analysis for Her2/neu status was done using Clone: CB11 (Biogenenx).

\section{Statistical Analysis}

Descriptive and inferential statistical analysis has been carried out in the present study. Results on continuous measurements are presented on Mean \pm SD and results on categorical measurements are presented in number (\%). Significance is assessed at $5 \%$ level of significance. Student $t$ test has been used to find the significance of study parameters on continuous scale between two groups on metric parameters. Chi-square/ Fisher Exact test has been used to find the significance of study parameters on categorical scale between two or more groups. $\mathrm{P}$ value of $<0.05$ has been considered statistically significant. The statistical software SPSS 18.0, and $\mathrm{R}$ environment ver.3.2.2 were used for the analysis of data and Microsoft word and excel have been used to generate graphs.

\section{Results}

144 patients of breast cancer were included in this study. 63 patients $(43.75 \%)$ were excluded due to advanced stage of the disease and 81 patients $(56.25 \%)$ of early breast cancer were found to be eligible for this study. Out of 81 patients, 2 
patients had no palpable tumor mass and 1 patient had post lumpectomy status with positive resection margin. The tumor size was $\mathrm{T} 1(<2 \mathrm{~cm})$ in 15 patients $(18.6 \%)$ and $\mathrm{T} 2(2-5 \mathrm{~cm})$ in 63 patients $(77.8 \%)$. 25 patients $(30.9 \%)$ showed axillary metastases and the axillary lymph nodes dissected and examined varied from 6 to 24 with an average of 14.6. The correlation between tumor size and axillary metastasis was found to be significant in this study $(\mathrm{p}=0.045)$.

The mean age of the patient at the time of surgery was $50.8 \pm 12.92$ which ranged from 29 to 80 years. No correlation was observed between patient's age and axillary metastasis in this study $(\mathrm{p}=0.509)$. On immunohistochemistry, ER and PR negative patients were found to be significantly associated with low risk of axillary nodal metastasis $(\mathrm{p}=0.023)$ but Her2/neu status was not found to be statistically significant.

On histological typing of breast cancer, 71 cases $(87.7 \%)$ were infiltrating ductal carcinoma-NOS. Significant correlation was noted between histological type of tumor and axillary nodal metastasis $(\mathrm{p}=0.038)$. Tumors like medullary carcinoma, infiltrating lobular carcinoma, mucinous carcinoma and DCIS showed less tendency for axillary metastasis compared to infiltrating ductal carcinoma-NOS.

Other variables like histological grading of the tumor, side of the breast involved, lymphovascular invasion and perineural spread were not found to be associated with axillary lymph node metastasis in early breast cancer.

Patient and tumor characteristics and related statistical analysis-

\begin{tabular}{|c|c|c|c|c|}
\hline Factor & $\begin{array}{l}\text { Total Number Of } \\
\text { Patients }(\mathrm{n}=81)\end{array}$ & $\begin{array}{c}\text { Node Positive } \\
(\mathrm{n} 1=25)\end{array}$ & $\begin{array}{c}\text { Node Negative } \\
(\mathrm{n} 2=56)\end{array}$ & P-Value \\
\hline $\begin{array}{l}\text { Age groups } \\
<40 \text { years } \\
40-60 \text { years } \\
>60 \text { years }\end{array}$ & $\begin{array}{l}19 \\
45 \\
17\end{array}$ & $\begin{array}{c}7 \\
13 \\
5\end{array}$ & $\begin{array}{l}12 \\
32 \\
12\end{array}$ & 0.509 \\
\hline $\begin{array}{l}\text { Side of the breast involved } \\
\text { Left } \\
\text { Right } \\
\text { Not specified }\end{array}$ & $\begin{array}{l}47 \\
32 \\
2\end{array}$ & $\begin{array}{c}16 \\
9 \\
0\end{array}$ & $\begin{array}{l}31 \\
23 \\
2\end{array}$ & 0.628 \\
\hline $\begin{array}{l}\text { Tumor Size } \\
\text { No tumor mass } \\
\text { Post lumpectomy } \\
\text { T1 }(<2 \mathrm{~cm}) \\
\text { T2 }(2-5 \mathrm{~cm})\end{array}$ & $\begin{array}{c}2 \\
1 \\
15 \\
63 \\
\end{array}$ & $\begin{array}{c}1 \\
1 \\
3 \\
20 \\
\end{array}$ & $\begin{array}{c}1 \\
0 \\
12 \\
43 \\
\end{array}$ & $0.045^{*}$ \\
\hline $\begin{array}{l}\text { Hormonal status } \\
\text { ER+/PR+ } \\
\text { ER+/PR- } \\
\text { ER-/PR+ } \\
\text { ER-/PR- } \\
\end{array}$ & $\begin{array}{c}15 \\
11 \\
1 \\
54\end{array}$ & $\begin{array}{c}5 \\
7 \\
0 \\
13 \\
\end{array}$ & $\begin{array}{c}10 \\
4 \\
1 \\
41\end{array}$ & $0.023^{*}$ \\
\hline $\begin{array}{l}\text { Her2/neu status } \\
\text { Negative } \\
\text { Positive } \\
\end{array}$ & $\begin{array}{l}37 \\
44 \\
\end{array}$ & $\begin{array}{l}14 \\
11 \\
\end{array}$ & $\begin{array}{l}23 \\
33 \\
\end{array}$ & 0.169 \\
\hline $\begin{array}{l}\text { Lymphovascular invasion } \\
\text { Absent } \\
\text { Present }\end{array}$ & $\begin{array}{l}38 \\
43 \\
\end{array}$ & $\begin{array}{c}9 \\
16 \\
\end{array}$ & $\begin{array}{l}29 \\
27 \\
\end{array}$ & 0.188 \\
\hline $\begin{array}{l}\text { Perineural spread } \\
\text { Absent } \\
\text { Present }\end{array}$ & $\begin{array}{l}67 \\
14 \\
\end{array}$ & $\begin{array}{c}20 \\
5 \\
\end{array}$ & $\begin{array}{c}47 \\
9 \\
\end{array}$ & 0.666 \\
\hline $\begin{array}{l}\text { Histological type } \\
\text { Infiltrating ductal carcinoma-NOS } \\
\text { Medullary carcinoma } \\
\text { Infiltrating lobular carcinoma } \\
\text { Mucinous carcinoma } \\
\text { Tubular carcinoma } \\
\text { Metaplastic carcinoma (SCC) } \\
\text { DCIs }\end{array}$ & $\begin{array}{c}71 \\
2 \\
4 \\
1 \\
1 \\
1 \\
1 \\
\end{array}$ & $\begin{array}{c}23 \\
0 \\
1 \\
0 \\
0 \\
1 \\
0 \\
\end{array}$ & $\begin{array}{c}48 \\
2 \\
3 \\
1 \\
1 \\
0 \\
1 \\
\end{array}$ & $0.038^{*}$ \\
\hline $\begin{array}{l}\text { Histological grade } \\
\text { Not available } \\
\text { Grade I } \\
\text { Grade II } \\
\text { Grade III } \\
\end{array}$ & $\begin{array}{c}9 \\
4 \\
8 \\
60 \\
\end{array}$ & $\begin{array}{c}2 \\
1 \\
4 \\
18 \\
\end{array}$ & $\begin{array}{r}7 \\
3 \\
4 \\
42 \\
\end{array}$ & 0.672 \\
\hline
\end{tabular}




\section{Discussion}

Breast cancer is the most common cancer among women in India ${ }^{[10]}$. Mastectomy with ALND is the gold standard in determining the prognosis, adjuvant therapy and loco-regional control and improves the survival rate amongst the node positive group ${ }^{[1,12]}$. With advances in radiotherapy and surgical techniques, breast conservation surgery (BCS) along with sentinel lymph node biopsy (SLNB) is considered equivalent to mastectomy with ALND for the treatment of early breast cancer ${ }^{[13,14]}$. However, as mammography screening for breast cancer becomes more prevalent, breast tumors are being diagnosed at smaller sizes as well as at node negative status. The node negative patients do not benefit from ALND but may suffer from various early complications like infection, seroma and hematoma as well as late complications like limb edema, paraesthesia, stiffness, pain and weakness of the the involved limb and psychological distress ${ }^{[15]}$.

SLNB is associated with less morbidity. But, it has its own limitations and pitfalls. The use of radioisotopes require a licence and it is not available in every center. The use of blue dye such as isosulfan blue is associated with adverse reactions including anaphylaxis in some patients. Patient's age and location of the primary tumor also affect the success rate of SLN identification leading to false negative results ${ }^{[16,17]}$. In older patients, the ability of lymph nodes to retain the radioisotope or dye may be decreased because of replacement of nodal tissue by fat. Also, the tumors located medially have high rates of failure because they are related to the lymphatic drainage to the internal mammary lymph nodes and the SLNB of these nodes are not performed. The internal mammary lymph nodes have the same prognostic significance as axillary nodal metastasis ${ }^{[18,19]}$. O'Hea et al reported that the accuracy of SLNB decreases with the increasing tumor size ${ }^{[20]}$. As large tumors are likely to involve more than one lymphatic trunk and some lymphatics may be blocked with tumor calls. In this situation, lymphatic drainage may be diverted from the true SLN to collateral lymph nodes that may not contain metastatic disease. Another drawback of SLNB is that patient will be required to undergo another surgery under general anaesthesia for completion axillary clearance, if axillary lymph nodes are positive. Thus, this study is aimed at determining preoperative factors with the help of which we can define subgroups of patients who will be at lower risk for axillary lymph node metastases, so that we can avoid unnecessary axillary dissection.

$70-80 \%$ of the patients in western countries have histologically negative nodes ${ }^{[21]}$. In this study, 56 patients $(69.1 \%)$ had negative axillary nodes. This suggests that upto $69 \%$ patients of early breast cancer in this study did not benefit from ALND instead they may suffer from its complications.

There have been several studies aimed at determining the predictive factors to define subgroups of patients who will be at lower risk for axillary lymph node metastasis. To our knowledge, this is the first study in this part of country based on determination of predictive factors responsible for axillary metastasis.

In this study, 64 patients (79\%) were below 60 years of age and no significant correlation was found between patient's age and axillary metastasis. Many studies evaluating the influence of age on outcome in breast cancer have had conflicting results. Two relatively large trials have, however, demonstrated a worse prognosis of patients younger than 35 years, even after adjustment for other prognostic factors [22,23]. However, the size of the tumor and the histological type of the tumor were found to have significant correlation with axillary metastasis in this study which is in consistent with the previous studies. Larger tumor size was found to be an independent predictor of node positive disease in our study, concurring with the data from several other centres ${ }^{[24-26]}$. Previous studies also suggest a significant relationship between tumor size and recurrence free survival. Rosen et al examined the relationship between tumor size and 20-year 
recurrence free survival and found a significant association with a 20 -year recurrence free survival of $88 \%$ of tumors $\leq 1 \mathrm{~cm}, 72 \%$ of tumors 1.1 to 3 $\mathrm{cm}$ and $59 \%$ for tumors between $3.1 \mathrm{~cm}$ to $5 \mathrm{~cm}$ [27].

Further, infiltrating ductal carcinoma-NOS showed higher rate of axillary metastasis compared to DCIS, tubular, mucinous, medullary or infiltrating lobular carcinoma. It is documented that certain histological types have favorable prognosis than non specified cancers ${ }^{[28]}$. It had also been shown previously that patients with high grade tumors have significant high frequency of axillary metastasis ${ }^{[29,30]}$. But, this study failed to establish a significant relation between tumor grade and axillary metastasis.

As far as immunohistochemistry is concerned, this study suggested that ER and PR negative status was significantly associated with low risk of axillary nodal metastasis whereas Her2/neu was not found to be significant. One study suggested that the ER and PR levels do not contribute to the predictors of axillary nodal metastasis since there was no correlation with node positivity ${ }^{[31]}$. However, there were documented contrasting reports also which suggested that the presence of ER and PR is both predictive factor mainly for the benefit of adjuvant tamoxifen therapy as well as prognostic factor in breast cancer ${ }^{[28]}$. But, the interpretation of many studies of Her $2 /$ neu is limited by variability in the methods used to detect overexpression, definition of positivity and the most are retrospective studies. Some studies suggested that HER2/neu overexpression is associated with increased tumor aggressiveness, increased rates of recurrence and increased mortality in node positive patients while the influence in node negative patients are more variable $^{[32-35]}$.

The correlation between lymphovascular invasion (LVI) and axillary node metastasis was not significant in this study. However, a study conducted by Lauria et al showed prognostic value of LVI in operable breast cancer and its positive correlation with metastatic axillary lymph nodes ${ }^{[36]}$. Other factors such as perineural spread and side of the breast involved were also found to be not significant predictive factors in determining the axillary metastasis in early breast cancer.

Certain predictive factors can be determined preoperatively with the help of various imaging modalities and trucut biopsies. The findings of this study are based on the retrospective analysis of postoperative data. We feel that a large scale prospective study is needed to confirm them and establish the predictive factors responsible for axillary metastasis in early breast cancer. This will in turn improve the preoperative assessment and planning and will reduce the postoperative morbidity. However, all the cases in this study were operated by a single surgeon and the HPE analysis was done by a single expert pathologist which gives strength to this study as it eliminates the chance of interpersonal bias.

In conclusion, we have found that size of the tumor, hormonal status and histological type of the tumor can predict the axillary metastasis in early breast cancer which can be taken into consideration before going for ALND in node negative patients. However, further studies are required to define the selection criteria of early breast cancer patients in whom ALND can be avoided.

\section{References}

1. Siegel R, Naishadham D, Jemal A. Cancer statistics, 2013. CA cancer J Clin. 2013;63:11-30.

2. Murthy NS, Juneja A, Sehgal A, Parbhakar AK, Luthra UK. Cancer projection by the turn of the country- Indian Scene. Ind J Cancer 1990;27:74-82.

3. Cianfrocca M, Goldstein LJ. Prognostic and Predictive factors in Early-Stage Breast Cancer. The Oncologist 2004;9: 606-16.

4. Hoe Al, Iven D, Royle GT. Incidence of arm swelling following axillary clearance for breast cancer. Br J Surg 1992;79:26162. 
5. Jatoi I. Management of the axilla in primary breast cancer. SurgClin North Am 1999;79:1061-73.

6. Naik AM, Fey j, Gemignani M. The risk of axillary relapse after sentinel lymph node biopsy for breast cancer is comparable with that of axillary lymph node dissection. A follow-up study of 4008 procedures. Ann Surg 2004;240:462-71.

7. Jeruss JS, Winchester DJ. Axillary recurrence after Sentinel Node Biopsy. Ann Surgoncol 2005;12:34-40.

8. Purushotham AD, Upponi S, Klevesath MB, Bobrow L, Millar K, Myles JP et al. Morbidity after sentinel lymph node biopsy in primary breast cancer: results from a randomized controlled trial. J ClinOncol. 2005;19:4312-21.

9. Krag DN, Anderson SJ, Julian TB, Brown AM, Harlow SP, Ashikaga $\mathrm{T}$ et al. Technical outcomes of sentinel lymph node resection and conventional axillary lymph node dissection in patients with clinically node negative breast cancer: results from the NSABP B-32 randomised phase III trial. LanOncol. 2007;10:881-8.

10. Murthy NS, Chaudhry K, Nadayil D, Agarwal UK, Saxena S. Changing trends in incidence of breast cancer: Indian scenario. Indian J Cancer 2009;46:73-4.

11. Moore MP, Kinne DW. Axillary lymphadenectomy: a diagnostic and therapeutic procedure. Surgoncol 1997;66:2-6.

12. Carter CL, Allen C, Henson DE. Relation of tumors size,lymph node status and survival in 24,740 breast cancer cases. Cancer 1989;63:181-87.

13. Newman LA, Kuerer HM. Advances in breast conservation therapy. J ClinOncol 2005;23:1685-97.

14. Woon YY, Chan MYP. Breast conservation surgery- the surgeon's factor. Breast 2005;14;131-35.
15. Alastair M, Thompson. Axillary node clearance for breastcancer. J R CollSurgEdinb1999;44:111-17.

16. Krag D, Weaver D, Ashikaga T. The sentinel node in breast cancer: A multicenter validation study. New Engl J Med 1998;339:941-46.

17. Noguchi M, Motomura K, Imoto S. A multicenter validation study of sentinel lymph node biopsy by the JapaneseBreast Cancer Society. Breast Cancer Res Treat 2000;63:31-40.

18. Veronesi U,Cascinelli N, Greco M. Prognosis of breastcancer patients after mastectomy and dissection of internal mammary nodes. Ann Surg 1985;202:70207.

19. Noguchi M, Ohta N, Koyasaki N. Reappraisal of internal mammary node metastases as a prognostic factor in patients with breast cancer. Cancer 1991;68:1918-25.

20. O'Hea BJ, Hill ADK, El-Shirbiny AM. Sentinel lymphnode biopsy in breast cancer: initial experience at Memorial Sloan-Kettering Cancer Center. J Am CollSurg 1998;186:423-27.

21. Jatoi I. Management of the axilla in primary breast cancer.SurgClin N Am 1999;79:1061-73.

22. Nixon AJ, Neuberg D, Hayes DF. Relationship of patientage to pathologic features of the tumor and prognosis for patients with stage I or II breast cancer. J ClinOncol 1994;12:888-94.

23. Albain KS, Allred DC, Clark GM. Breast cancer outcome andpredictors of outcome: are there age differentials? J Natl Cancer Inst Mongr 1994;16:35-42.

24. Yiangou C, Shousha S, Sinnett HD. Primary tumour characteristicsand axillary lymph node status in breast cancer. $\mathrm{Br} \mathbf{J}$ Cancer 1999;80:1974-8.

25. Chua B, Ung O, Taylor R. Frequency and predictors ofaxillary lymph node 
metastases in invasive breast cancer. ANZ JSurg 2001;71:723-8.

26. Olivotto IA, Jackson JS, Mates D. Prediction of axillarylymph node involvement of women with invasive breast carcinoma:a multivariate analysis. Cancer 1998;83:948-55.

27. Rosen PP, Groshen S, Kinne. Factors influencingprognosis in node-negative breast carcinoma: analysis of 767T1N0M0/T2N0M0 patients with longterm follow-up. J ClinOncol 1993;11: 2090-2100.

28. Tan LGL, Tan YY, Heng D, Chan MY. Predictors ofaxillary lymph nodemetastases in women with early breast cancerin Singapore. Singapore Med J 2005;46(12): 693-97.

29. Henson DE. Histological grading of breast cancer: Significance of grade on recurrence and mortality. Arch PatholLab Med 1988;112:1091-96.

30. Hapton DS, Thorogood J, Clayden AD. Histologicalgrading of breast cancer: significance of grade on recurrence andmortality. Eur J SurgOncol 1989;15:25-31.

31. Hlgreno J, Tal L, Estman G, Nesson L-G. Prediction of axillary lymph node metastases in screened breast cancerpopulation. ActaOncol1994;33(6):603-08.

32. Borg A, Tandon AK, Sigurdsson H. HER2/neuamplificationpredicts poor survival in node-positive breast cancer. Cancer Res 1990;50:4322-27.

33. Winstanley J, Cooke T, Murray GD. The long term prognosticsignificance of c-erb2 in primary breast cancer. $\mathrm{Br} \mathrm{J}$ Cancer 1991;63:447-50.

34. Paterson MC, Dietrich KD, Danyluk J. Correlationbetween c-erb-2 amplification and risk of recurrent disease innode- negative breast cancer. Cancer Res 1991;51:566-67.

35. Clark GM, McGuire WL. Follow-up study of HER-2/neuamplification in primary breast cancer. Cancer Res 1991;51:944-48.

36. Lauria R, Perrone F, Carlomagno C. The prognostic value oflymphatic and blood vessel invasion in operable breast cancer. Cancer 1995;76:1772-78. 